\title{
Review of methodological developments in laser Doppler flowmetry
}

\author{
Vinayakrishnan Rajan • Babu Varghese • \\ Ton G. van Leeuwen • Wiendelt Steenbergen
}

Received: 24 July 2007 / Accepted: 24 October 2007 / Published online: 31 January 2008

(C) Author(s) 2007

\begin{abstract}
Laser Doppler flowmetry is a non-invasive method of measuring microcirculatory blood flow in tissue. In this review the technique is discussed in detail. The theoretical and experimental developments to improve the technique are reviewed. The limitations of the method are elaborated upon, and the research done so far to overcome these limitations is critically assessed.
\end{abstract}

Keywords Laser Doppler flowmetry · Microcirculation ·

Diagnostic imaging $\cdot$ Doppler effect

$\begin{array}{ll}\text { Abbreviations } \\ \text { LDF } & \text { Laser Doppler flowmetry } \\ \text { LDPM } & \text { Laser Doppler perfusion monitoring } \\ \text { LDPI } & \text { Laser Doppler perfusion imaging } \\ \text { LASCA } & \text { Laser speckle contrast analysis } \\ \text { VCSEL } & \text { Vertical cavity surface emitting laser } \\ \text { CMOS } & \text { Complementary metal oxide semiconductor } \\ \text { CCD } & \text { Charge-coupled device } \\ \text { BZ } & \text { Biological zero }\end{array}$

\section{Introduction}

Laser Doppler flowmetry (LDF) is a non-invasive diagnostic method of measuring blood flow in tissue. The technique is based on measuring the Doppler shift [1] induced by moving

V. Rajan $(\bowtie) \cdot$ B. Varghese $\cdot$ T. G. van Leeuwen $\cdot$ W. Steenbergen Institute of Biomedical Technology,

Biophysical Engineering Group,

University of Twente,

P.O. Box 217,

7500AE Enschede, The Netherlands

e-mail: v.rajan@tnw.utwente.nl red blood cells to the illuminating coherent light. A laser Doppler instrument output often gives flux, velocity and concentration of the moving blood cells. These parameters are extracted from the power spectrum of the photocurrent fluctuations produced by reflected light illuminating a photodetector. There are two types of perfusion measurements in practice, laser Doppler perfusion monitoring (LDPM) and laser Doppler perfusion imaging (LDPI).

Since the commercialization of the technique in the early 1980s, LDF has had a modest but stable and steadily growing commercial market. Figure 1 illustrates the growth of the use of LDF in research by the number of peer-reviewed articles published each year ${ }^{1}$ in which laser Doppler flowmetry techniques have been used (LDPM and LDPI).

Other techniques that were used for blood flow measurements before the evolution of the laser Doppler technique were the xenon washout technique [2] and the radioactively labeled microsphere technique [3, 4]. These techniques require an injection of a radioactive substance into the blood stream.

Doppler ultrasound methods to measure blood flow are non-invasive but incapable of measuring the microcirculation. In Table 1 various techniques to measure skin blood flow are compared.

The major advantage of the laser Doppler techniques in general is their non-invasiveness and their ability to measure the microcirculatory flux of the tissue and fast changes of perfusion during provocations. The technique can measure perfusion quantitatively (although relative) in real time.

\footnotetext{
${ }^{1}$ Web of Science (ISI Web of Knowledge), search terms: [(laser and Doppler) or (laser-Doppler)] and (perfusion or microcirculation or flowmetry).
} 


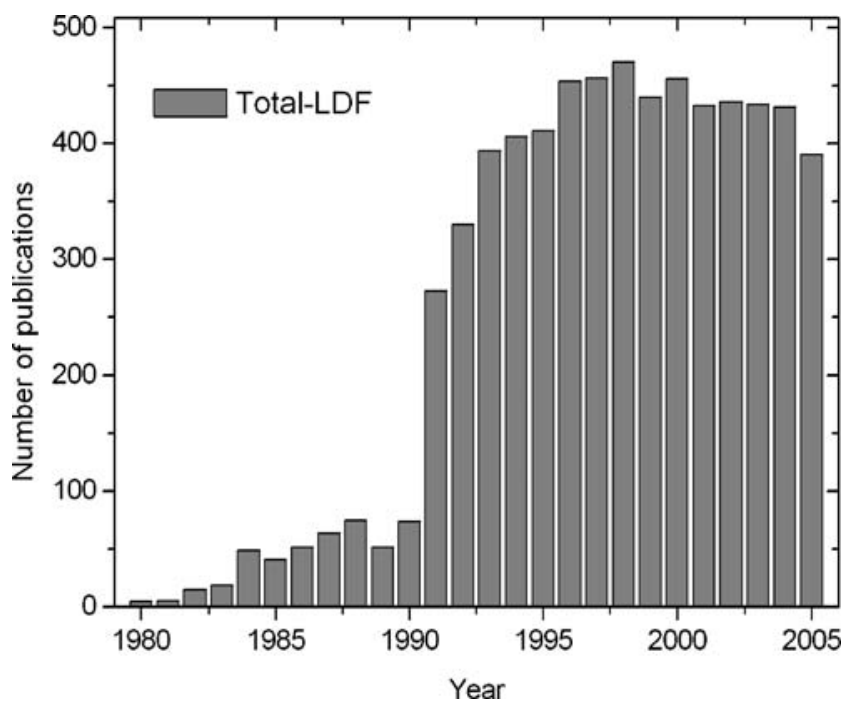

Fig. 1 Statistics of publications using LDF techniques from 1980 till 2006

There are some limitations of the technique. The major limitations are the influence of the tissues' optical properties on the perfusion signal, motion artifact noise, lack of quantitative units for perfusion, lack of knowledge of the depth of measurement and the biological zero signal (perfusion measured at no flow condition). These limitations motivate ongoing research in both the instrumentation and theoretical aspects of the technique.

Laser Doppler flowmetry techniques for measuring blood flow have been reviewed by many authors considering different aspects of the technique. Early developments in laser Doppler flowmetry and its clinical applications were reviewed by Shepherd and Öberg [10]. Obeid et al. [12] reviewed the limitations of the technique. In a later review Vongsavan and Matthews [13] compared the performance of two instruments which were then widely used in clinics: the Periflux model PF3 (Perimed, Stockholm, Sweden) and the Moor blood flow monitor model MBF3D/ 42 (Moor Instruments, Axminster, Devon, UK). Leahy et al. [14] reviewed the principles and use of laser Doppler instruments and discussed different aspects of the method. In a recent review Briers [9] compared laser Doppler techniques with speckle techniques, which progressed in parallel. A review of the techniques of whole-field blood

Table 1 Methods of measuring skin blood flow

\begin{tabular}{|c|c|c|c|c|}
\hline Technique & $\begin{array}{l}\text { Non- } \\
\text { invasive? }\end{array}$ & Principle & Measured quantity & Disadvantages \\
\hline $\begin{array}{r}\text { Fluorescent } \\
\text { tracers }[5]\end{array}$ & No & $\begin{array}{l}\text { A fluorescent dye is injected into the blood } \\
\text { stream. Tissue fluorescence is taken as an } \\
\text { indication of blood flow }\end{array}$ & $\begin{array}{l}\text { Blood flow } \\
\text { distribution }\end{array}$ & $\begin{array}{l}\text { No quantitative measurement. } \\
\text { Cannot study fast changes in blood } \\
\text { flow }\end{array}$ \\
\hline $\begin{array}{l}\text { Radioactive } \\
\text { microsphere } \\
\text { technique [3] }\end{array}$ & No & $\begin{array}{l}\text { Radioactive microspheres are injected inti the } \\
\text { blood stream; mean blood flow is estimated } \\
\text { from the recovered isotope count from } \\
\text { excised tissue }\end{array}$ & Mean blood flow & $\begin{array}{l}\text { Tissue needs to be excised for the } \\
\text { measurement; no real time } \\
\text { measurement possible }\end{array}$ \\
\hline $\begin{array}{l}{ }^{133} \text { Xe wash out } \\
\text { technique [2] }\end{array}$ & No & $\begin{array}{l}{ }^{133} \mathrm{Xe} \text { is injected subdermally. The rate of } \\
\text { clearance is a measure of blood flow }\end{array}$ & Absolute blood flow & $\begin{array}{l}\text { Point measurement. Does not give } \\
\text { information about regional blood } \\
\text { flow. Measures only one or few } \\
\text { capillaries }\end{array}$ \\
\hline $\begin{array}{l}\text { Capillary } \\
\text { microscopy [6] }\end{array}$ & Yes & $\begin{array}{l}\text { The distance traveled by erythrocytes in } \\
\text { successive frames gives a measure of blood } \\
\text { velocity }\end{array}$ & $\begin{array}{l}\text { Capillary } \\
\text { distribution and } \\
\text { blood velocity }\end{array}$ & $\begin{array}{l}\text { Capillary perpendicular to the skin } \\
\text { surface cannot be visualized }\end{array}$ \\
\hline Thermography [7] & Yes & $\begin{array}{l}\text { Skin temperature radiation is imaged and is } \\
\text { related to the blood flow }\end{array}$ & $\begin{array}{l}\text { Temperature map of } \\
\text { the skin }\end{array}$ & $\begin{array}{l}\text { Skin temperature and blood flow are } \\
\text { not directly related }\end{array}$ \\
\hline $\begin{array}{l}\text { Doppler } \\
\text { ultrasound [8] }\end{array}$ & Yes & $\begin{array}{l}\text { Based on the Doppler shift imparted by } \\
\text { moving blood cells to the probing sound } \\
\text { waves }\end{array}$ & $\begin{array}{l}\text { Spatially resolved } \\
\text { velocity }\end{array}$ & $\begin{array}{l}\text { Resolution insufficient for smallest } \\
\text { vessels; sensitive to only one } \\
\text { velocity component }\end{array}$ \\
\hline $\begin{array}{l}\text { Speckle } \\
\text { techniques [9] }\end{array}$ & Yes & $\begin{array}{l}\text { Speckles generated by back-scattered photons } \\
\text { from the tissue analyzed in spatial and } \\
\text { temporal domain to estimate blood flow. }\end{array}$ & $\begin{array}{l}\text { De-correlation time } \\
\text { and speckle } \\
\text { contrast, related to } \\
\text { blood flow }\end{array}$ & $\begin{array}{l}\text { No spectral information; } \\
\text { quantitative measurement is not } \\
\text { possible }\end{array}$ \\
\hline $\begin{array}{l}\text { Laser Doppler } \\
\text { flowmetry [10] }\end{array}$ & Yes & $\begin{array}{l}\text { Based on the Doppler shift imparted by the } \\
\text { moving red blood cells to the probing light. }\end{array}$ & $\begin{array}{l}\text { Relative } \\
\text { concentration and } \\
\text { velocity of moving } \\
\text { red blood cells }\end{array}$ & $\begin{array}{l}\text { No absolute measurement; no depth } \\
\text { information }\end{array}$ \\
\hline $\begin{array}{l}\text { Doppler } \\
\text { OCT [11] }\end{array}$ & Yes & $\begin{array}{l}\text { Combination of Doppler velocimetry with } \\
\text { low-coherence optical interferometry }\end{array}$ & $\begin{array}{l}\text { Spatially resolved } \\
\text { velocity of moving } \\
\text { red blood cells }\end{array}$ & $\begin{array}{l}\text { Limited probing depth } 1-2 \mathrm{~mm} \text {; } \\
\text { sensitive to only one velocity } \\
\text { component }\end{array}$ \\
\hline
\end{tabular}


velocity measurement can be found in Vennemann et al. [15]. This article reviews laser Doppler velocimetry, laser speckle methods, and magnetic resonance and ultrasound techniques for particle image velocimetry, used for perfusion monitoring and velocity mapping.

In our article we review the developments in laser Doppler perfusion monitoring and imaging, with emphasis on recent advances. The methodological progress of the technique is followed in detail, and special emphasis is given to the limitations of techniques and the research in this regard. This review does not cover imaging methods based on Laser speckle contrast analysis (LASCA).

Working principle of LDF techniques

\section{Light scattering in tissue}

When a beam of laser light illuminates a small area of tissue, photons will be scattered by static and dynamic particles. The moving red blood cells will impart a Doppler shift to the photon, depending on the scattering angle, the wavelength and the velocity vector of the scatterer. If a wave with frequency $\omega$ is scattered from a moving particle with velocity $\mathbf{v}$ (Fig. 2), the Doppler shift can be written as: $\Delta \omega=|\mathbf{v}|\left|\mathbf{k}_{\mathbf{I}}-\mathbf{k}_{\mathbf{s}}\right| \cos \beta$, where $\mathbf{k}_{\mathbf{I}}$ is the incident wave vector, $\mathbf{k}_{\mathbf{s}}$ is the wave vector of the scattered wave, and $\beta$ is the angle between the velocity vector and the scattering vector, which is defined as $\left(\mathbf{k}_{\mathbf{I}}-\mathbf{k}_{\mathbf{s}}\right)$. With $\alpha$ the scattering angle and $\lambda$ the wavelength of the light in the medium, the Doppler shift can be written as $\Delta \omega=2(2 \pi / \lambda)|v|$ $\sin (\alpha / 2) \cos \beta$. In tissue with a large number of moving particles, and for sufficiently long photon path lengths, photons will undergo more than one Doppler shift, which will result in a range of Doppler-shifted frequencies. Moreover, the random orientation of microcirculatory blood vessels and randomization of the photons with different scattering events give rise to a range of Doppler shifts, even when all particles move at the same speed.

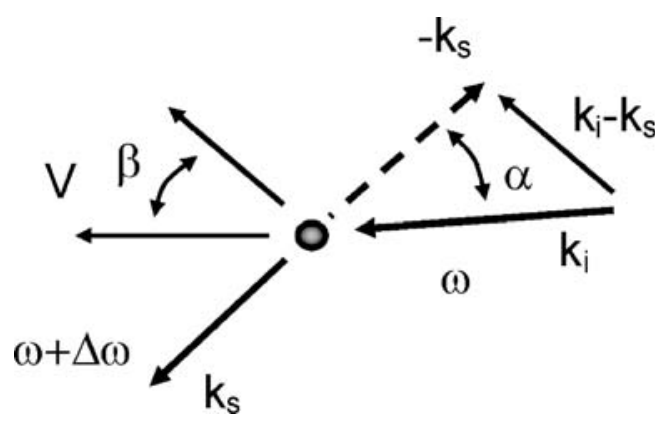

Fig. 2 Scattering of a photon with a wave vector $k_{I}$ and frequency $\omega$ by a moving red blood cell (RBC) with velocity $\mathrm{V}$

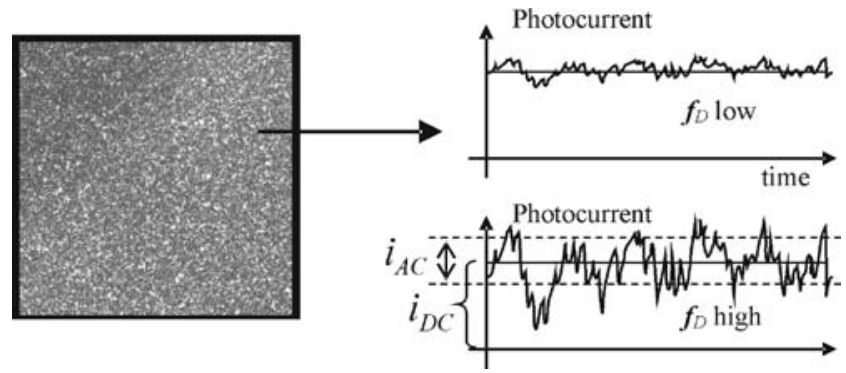

Fig. 3 Speckles generated by light back-scattered from a particle suspension. On the right is an illustration of the fluctuations in the photodetector intensity resulting from the dynamic speckle pattern. $f_{D}$ is the Doppler-shifted fraction of all detected photons

\section{Extraction of laser Doppler signal}

In laser Doppler flowmetry the interference of Dopplershifted light with non-Doppler shifted light on the photodetector generates a dynamic speckle pattern. As a result of these patterns, the detector's current signal will fluctuate. If the signal generated by the photodetector is from only Doppler-shifted light, it is called a homodyne signal in laser Doppler terminology. The scattering from a tissue matrix with a sufficiently small volume of blood (dynamic scatterers) will result in a signal that is produced mainly by interference of Doppler-shifted light with non-Doppler shifted light, a situation called heterodyne. It can be shown [16] that the alternating current (AC) signal generated by a fluctuating speckle pattern, normalized by the squared value of the direct current $\left(\mathrm{DC}^{2}\right)$, is equal to

$\frac{\left\langle i_{A C}^{2}\right\rangle}{\left\langle i_{D C}\right\rangle^{2}}=\frac{1}{N} f_{D}\left(2-f_{D}\right)$

with $\left\langle i_{A C}^{2}\right\rangle$ the mean square of the photocurrent fluctuations, $\left\langle i_{D C}\right\rangle$ the mean photocurrent, $N$ the number of speckles on the detector and $f_{D}$ the Doppler-shifted fraction of all detected photons. In this, it is assumed that the photodetector surface is, on average, homogeneously illuminated. Figure 3 illustrates the fluctuations in the intensity of the photodetector signal generated by dynamic speckle patterns.

To extract the flux and concentration of the moving blood cells, one must measure the power spectrum of the detector's current fluctuations. Figure 4 shows such a spectrum (averaged over 500 spectra), obtained from laser light back-scattered from the right cheek of a human subject. The moment of order $i$ of the power spectrum is defined as

$M_{i}=\int_{0}^{\infty} \omega^{i} P(\omega) d \omega$ 


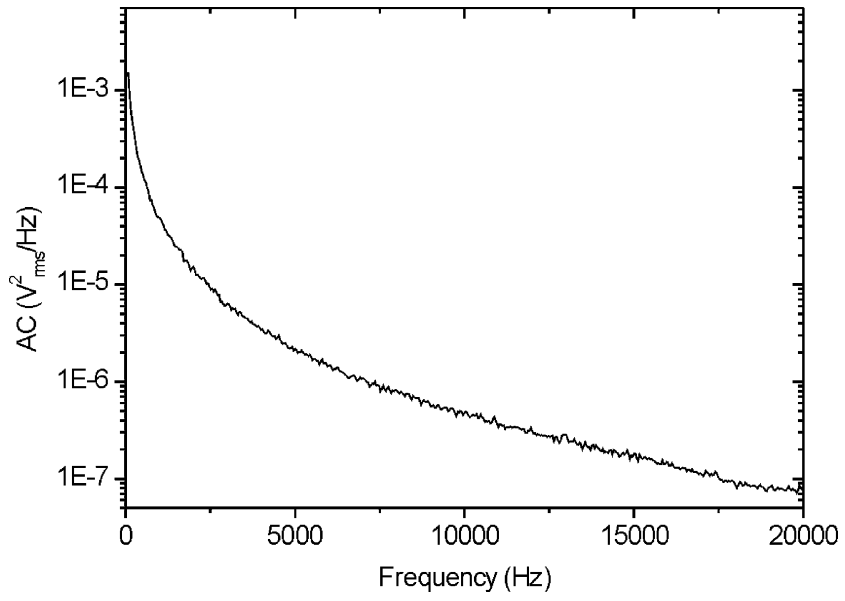

Fig. 4 Power spectrum of the laser Doppler signal measured from human skin in vivo

Bonner and Nossal [17] showed that the first moment, $i=1$ in Eq. 2, is linearly proportional to the root mean square (r.m.s.) velocity of moving red blood cells and its concentration, provided the blood concentration is small (negligible multiple scattering). The first moment was defined as the perfusion signal, which is the average concentration multiplied by the average r.m.s. velocity of moving red blood cells (RBCs). The zero order moment $\left(\mathrm{M}_{0}\right)$ is equal to the modulation depth of the photocurrent, as defined by Eq. 1 and is proportional to the concentration of moving red blood cells, and, hence, the weighted first moment $\left(\mathrm{M}_{1} / \mathrm{M}_{0}\right)$ gives the average Doppler shift (proportional to the average velocity) imparted by the moving blood cells. Since the laser Doppler instrument cannot present blood flow in absolute values, perfusion is expressed in terms of arbitrary perfusion units (PUs).

In arriving at the expression relating blood flow and moments of the power spectra, Bonner and Nossal [17] used the following assumptions: (1) light is randomized in direction in all tissues, independent of blood flow and blood volume; (2) Doppler shift due to blood flow principally arises from the scattering of diffuse light from moving red blood cells; (3) the mean number of RBCs by which a typical detected photon is Doppler shifted increases linearly with the number and density of RBCs flowing within the microcirculation; (4) Doppler broadening is increased by multiple scattering from more than one moving red blood cell. Moreover, the linear relationship depicted by the model between first moment and the concentration of RBCs is valid only for small fractions of red blood cells (negligible multiple scattering).

\section{Laser Doppler perfusion monitor}

A laser Doppler perfusion monitor uses a fiber-optic probe with one multimode fiber to deliver the laser light, often from a semiconductor laser diode, to the tissue, and another multimode fiber to detect the back-scattered photons (Fig. 5a). It is a one-point measurement method, which records the integrated perfusion in a sampling volume in real time. The measurement depth and sampling volume depend on the wavelength and the fiber separation used. In normal skin, and with laser Doppler instruments with a probe with standard fiber separation $(0.25 \mathrm{~mm})$ and $780 \mathrm{~nm}$ wavelength, the measuring depth is $0.5-1 \mathrm{~mm}$ and the measurement volume is approximately $1 \mathrm{~mm}^{3}$. In LDPM, often the perfusion signal is normalized with $\mathrm{DC}^{2}$ to make readings independent of the actual laser power.

The main manufacturers of laser Doppler instruments are Perimed AB (Stockholm, Sweden), Moor Instruments Ltd. (Axminster, UK), Transonic Systems Inc. (Ithaca, New York, USA), Oxford Optronix Ltd (Oxford, UK) and LEA Medizintechnik (Giessen, Germany). The wavelengths used most often by these systems are $630 \mathrm{~nm}, 780 \mathrm{~nm}$ and $830 \mathrm{~nm}$, with typical fiber-to-fiber distances of $0.25 \mathrm{~mm}$, $0.5 \mathrm{~mm}$ and $0.78 \mathrm{~mm}$ (except for the instruments by LEA, see the section "Signal processing in laser Doppler flowmetry").

\section{Laser Doppler perfusion imager}

A laser Doppler perfusion imaging instrument maps the perfusion from a larger area by scanning the laser beam over the area of interest. Figure $5 \mathrm{~b}$ illustrates the schematics of a scanning laser Doppler perfusion imager. The advantage of this instrument over the monitor is that it is noncontact in nature, so it can be used in clinical situations

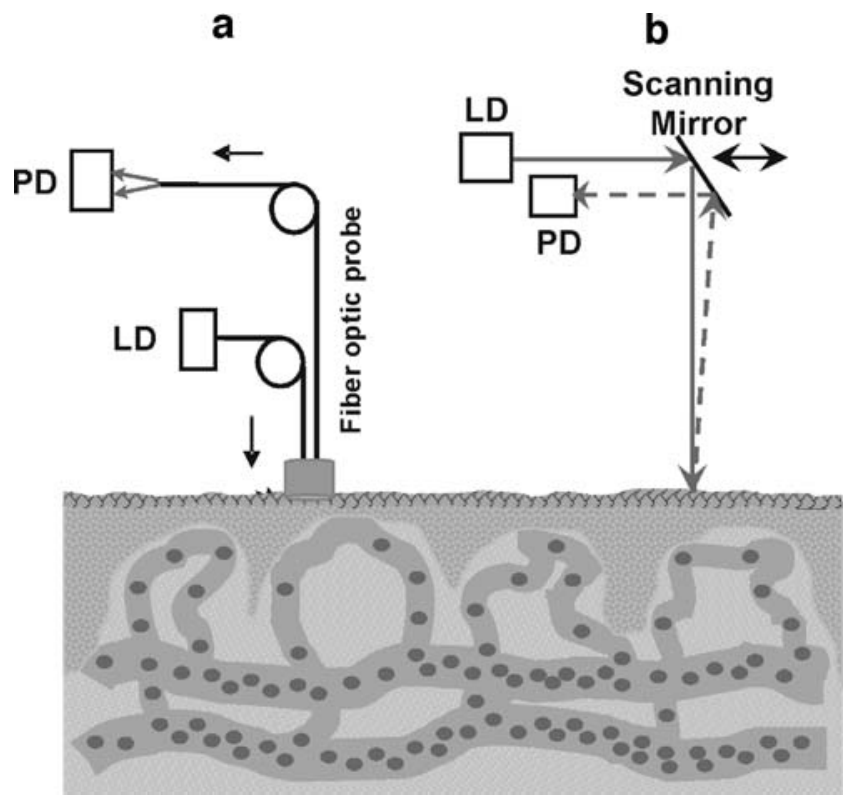

Fig. 5 An illustration of (a) LDPM and (b) LDPI geometries on a tissue model. $L D$ laser diode, $P D$ photodetector 
where contact with the tissue may be undesirable. Also, it gives a perfusion map of an area which gives average perfusion in a heterogeneous tissue in a single measurement. In LDPI we often find DC normalization, probably because that gives better results for heterogeneous tissue surfaces.

The main manufacturers of laser Doppler perfusion imagers are Perimed $\mathrm{AB}$ and Moor Instruments Ltd. The latest imager, model PIM3, of Perimed AB uses stepwise scanning of laser beam $(670-690 \mathrm{~nm}$, beam diameter $1 \mathrm{~mm}$ ). A complete scan of an area of $5 \mathrm{~cm} \times 5 \mathrm{~cm}$ (up to $50 \mathrm{~cm} \times 50 \mathrm{~cm}$ is possible), with a resolution of 256 pixels $\times$ 256 pixels, takes $4-5 \mathrm{~min}$, for a $25 \mathrm{~cm}$ distance of scanning head from the imaging surface. The spatial resolution of the image is $1 \mathrm{~mm}$ and is limited by the beam diameter.

Moor Instruments Ltd. use a continuously scanning beam and include different lasers in their imaging systems $(633 \mathrm{~nm}, 785 \mathrm{~nm}$ and $830 \mathrm{~nm})$; also, a dual wavelength system is available. The spatial resolution of the image is typically $1 \mathrm{~mm}$, and a high-resolution version is also available $(0.1 \mathrm{~mm})$. The scanning time is approximately $6 \mathrm{~min}$ for a $50 \mathrm{~cm} \times 50 \mathrm{~cm}$ image at 256 pixel $\times 256$ pixel resolution, at a speed of $4 \mathrm{~ms} / \mathrm{pixel}$ and at a $100 \mathrm{~cm}$ distance.

\section{Recent theoretical developments}

Attempts towards velocity-resolved measurement of perfusion by laser Doppler techniques

For a proper physiological interpretation of laser Doppler measurements, it would be useful to extract the velocity distribution of red blood cells from the power spectrum. As explained in the theory, to obtain an absolute velocity measurement one needs to know the scattering angle $(\alpha)$, the angle between the velocity vector and the scattering wave vector $(\beta)$, and the number of Doppler shifts in the case of multiple scattering. Dörschel and Müller [18] tried to solve the problem of the angle $\beta$ (angle $\varphi$ in their manuscript) with the assumption of an isotropically distributed angle between the velocity and the scattering vector and calculated a corrected frequency spectrum as if all vectors were parallel. The spectrum was corrected for various directions of velocity and reference vector by multiplication of the Doppler shift by the differential coefficient of the spectrum, which ultimately will lead to a velocity-resolved flow measurement.

Even though the approach is theoretically valid only for a fixed relationship between the scattering vector and the direction of the moving scatterer, remarkable results were obtained from the phantom measurements. The problem of non-constant scattering angle and influence of multiple Doppler shifts were limitations of their approach.
Larsson and Strömberg [19] proposed a method to extract concentration measurements of RBCs associated with a certain absolute velocity. They estimated the concentration by fitting Monte Carlo-derived Doppler spectra, arising from known velocities, to the measured Doppler power spectrum. It was assumed that if multiple Doppler shifts are negligible the power spectrum formed by a laser Doppler instrument can be considered to be from a number of single-velocity spectra,

$H_{\text {tot }}\left(\omega^{\prime}\right)=\sum_{i} c_{v_{i}} H_{v_{i}}\left(\omega^{\prime}\right)$

where $H_{t o t}$ is the multiple-velocity Doppler histogram, $c_{v_{i}}$ is the concentration of the scatterers that move with a velocity $v_{i}$, and $H_{v_{i}}$ is the normalized single-velocity Doppler histogram produced by the velocity $v_{i}$. In principle, by fitting the simulated single-velocity Doppler spectra to the measured spectra, one can extract the concentration of scatterers with that velocity. Experiments were done with both RBCs and microsphere suspensions. For Monte Carlo simulation of the Doppler spectra of RBCs, they used a two-parameter Gegenbaur kernel phase function to describe the light-scattering process. The results showed a good match between simulated and measured spectra. Experiments with single and double-tube flow phantoms confirmed the validity of their model to extract concentrations associated with related absolute velocities.

There are some limitations in the model. It works with only single Doppler scattering and very low concentration suspensions. Also, an isotropic distribution of the light fluence was assumed for the simulation, which is valid only for photons traveling at least one reduced mean free path length $m f p$ '. Thus, the validity of the assumption is questionable if one considers the very low scattering levels used for the experiments. Also, the influence of the heterogeneity of the optical properties, multiple Doppler shifts and distribution of velocity components has to be addressed when one is considering the applicability of their model to real tissue.

Liebert et al. [20] also considered the decomposition of a spectrum into individual velocity components, similarly to Larsson and Strömberg [19]. Single-scattering Dopplershifted power spectra were assumed, and the concentration of a particular velocity component was calculated, by the solving of a model equation in which the power spectrum was defined by a set of linear equations composed of different frequency components. The calculated average concentration was used to find the distribution of concentrations of different velocity components by

$c(V)=\sum_{j=1}^{M} a_{v} h_{v}\left(\Delta f_{j}\right)$ 
where $a_{v}$ is a weighting factor, which they derived from their model. Here, the distribution of the Doppler-shifted probability $h_{\nu}\left(\Delta f_{j}\right)$ is summed over the frequency, which gives the distribution of probability of Doppler scattering events as a function of speed. The proposed model was able extract the distribution of adjacent velocities from power spectra, but it was valid only for single Doppler shifts and has not yet been validated experimentally.

\section{Modeling of deep perfusion measurements}

To interpret deep perfusion signals measured with a large source-detector spacing, one needs to address the problem of multiple Doppler shifts where the classical approach fails. Binzoni et al. [21] proposed an algorithm to model the power spectrum of the laser Doppler signal which can be fitted to the experimental spectra to calculate the r.m.s. velocity of the moving particles and the mean number of scattering events. Three unknown model parameters were defined as $\bar{m}, \nu$ and $\beta$, which are, respectively, the average number of collisions which a detected photon makes with a moving particle, the velocity of the particle and a factor that depends on the optical coherence of the signal at the detector surface. The authors found these parameters by fitting the model function describing the power spectrum to the measured data.

It was proved that the model worked, even at large interoptode spacing $(1.5 \mathrm{~cm})$ and $\bar{m}$ values greater than 1 (multiple scattering), where the classical Bonner and Nossal model fails. Another interesting result was that the model could calculate the mean velocity without the influence of concentration changes and the number of scattering events. This showed the advantage of the proposed method over the classical approach. There are few limitations in this model which prevent it from measuring the absolute flow. One of the model functions, $\beta$ (the coherence factor), shows large variations. Also, it is known [17] that $\beta$ depends on the optical properties of the tissue. Thus, to have reliable information, one should study the variation of $\beta$ further. The window of the spectrum chosen seems to be rather small $(8 \mathrm{kHz})$ when compared with the source-detector distance used. At the larger detector distances and measuring volumes considered in the study, a higher bandwidth of frequencies can be expected. Since the model considers large detector distances and multiple Doppler shifts, it is a good stepping stone for measuring the absolute r.m.s. velocity from laser Doppler perfusion data.

One of the limitations of the Bonner and Nossal model [17] is that it assumes a random/Brownian motion of the red blood cells. The actual speed distributions of red blood cells in tissue consist of a Brownian and a translational component. The translational component is particularly important for measuring the deep flow, where the contri- bution from larger arterioles is significant. Binzoni et al. [22] took into account the Brownian component and the translational component in the tissue perfusion. They proposed a theoretical model to calculate different moments in laser Doppler spectra, which contains the Brownian velocity and the translational velocity. Their proposed method is a rather complicated power series of the average number of photon collisions $\bar{m}$ and the translational velocity $V_{\text {trans. }}$. The model also deals with the biological zero problem in laser Doppler flowmetry, which is the observation of non-zero perfusion with complete arterial occlusion. It was claimed that, during arterial occlusion $V_{\text {trans }}=0$, which makes only the Brownian motion a contribution in their equation. Even though the validity of the assumptions was not verified experimentally, this approach was able show the limitation of the classical approach in dealing with the translational motion of the scatterers when multiple Doppler scattering is considered.

Lohwasser and Soelkner [23] suggested an LDF algorithm to calculate the average blood cell velocity in deep perfusion measurements with penetration ranging from $10 \mathrm{~mm}$ to $30 \mathrm{~mm}$. They matched measured spectra with analytical models of diffusion theory and Monte Carlo simulations. The spectra predicted by the diffusion model match well with the measured spectra in the case of large fiber separations. An analytical fit was defined, based on a simple equation:

$\log [S(f)]=c+\beta f$,

where $S(f)$ is the measured power spectrum and $\mathrm{c}$ and $\beta$ are constants. $1 / \beta$ is proportional to the average velocity, which is found from the measured spectra by analytical fitting. Here, a frequency window was defined for fitting based on a quality function that neglected low-frequency spectra ( $3 \mathrm{kHz}$ in their experiments). Based on the results, it was claimed that the perfusion in deep tissues could be measured without the influence of perfusion in superficial layers. This was particularly suitable for perfusion measurements in brain cortex, avoiding the influence of scalp perfusion. However, issues such as the influence of absorption and scattering on the model, independent of perfusion, were not discussed. Also, the selection of the frequency window would be critical when the perfusion of the superficial layer was very high, which would cause unwanted higher frequency components to appear in the selected window.

\section{Technical innovations and introduction of new methods based on laser Doppler flowmetry}

After the first publication by Stern [24] of the potential of the Doppler effect induced by blood cells to measure blood 
flow, it took several steps for laser Doppler flowmetry to evolve as a clinically applicable tool. The major steps in this regard started with Watkins and Holloway [25], who, followed by Stern [24], developed a processor for clinical applications. Later on, Bonner and Nossal [17] developed a signal processor with a well-defined theoretical base. This processor was further modified [26, 27] and was widely accepted by researchers and manufacturers.

A detailed review of early technical innovations (till 1990) in laser Doppler flowmetry can be found in [10]. Laser Doppler perfusion monitoring (LDPM), which is a one-point measurement technique, was then extended to produce a perfusion map of an area of tissue by stepwise scanning of the laser beam over the tissue surface, called laser Doppler perfusion imaging (LDPI). Essex and Byrne [28] developed a laser Doppler scanner that could produce an image of $500 \times 700 \mathrm{~mm}^{2}$ in $6 \mathrm{~min}$, with a spatial resolution of $3 \mathrm{~mm}$. A scanning mirror was used to steer the beam, which moved continuously over the measurement region. The back-scattered photons were collected by a lens system with a photodetector in focus. Following this, Wardell et al. [29] reported on a scanning laser Doppler system that did not use a lens in front of the detector. The system used a stepper motor to steer the beam in a stepwise manner over the measurement region. A correction factor was used, based on the distance of the source from the tissue surface. A flow simulator was used for the validation of the instrument.

In the next part of the review we discuss the recent technical developments in perfusion monitoring and imaging.

\section{Technical innovations in laser Doppler perfusion} monitoring

\section{Signal processing in laser Doppler flowmetry}

In order to estimate the perfusion from the Doppler broadened photodetector signal, several frequency-weighted signal-processing algorithms were developed [10]. Koelink et al. [30] developed a digital signal-processing method and compared this with the performance of analog signalprocessing methods. The digital method used a time-domain approach, based on the time derivatives of the photocurrent fluctuations. It was found that the digital signal processor was more accurate and had a large dynamic range. The automatic optimization of the amplification of the input signal in the digital processor was found to be user friendly, in comparison with the analog method. The bandwidth selection in signal processing is very critical [12] and should be sufficient for the coverage of the major frequency range of the signal, avoiding white noise. Chen et al. [31] developed an adaptive processing bandwidth adjustment in which the Doppler spectra were first fitted to a Lorentzian function and the bandwidth at half the maximum of the Lorentzian function was used as an indicator of the major frequency range of the signal. The processing bandwidth was then tuned according to the calculated bandwidth values.

\section{Depth sensitivity in $L D F$}

To achieve some degree of depth-resolved perfusion monitoring, some authors have considered either using different wavelengths $[32,33]$ or changing the source-todetector distance [34]. Since the optical absorption by blood and, to a smaller extent, the scattering level of the tissue differ significantly for green, red and infrared light, this may be utilized to measure the blood flow in tissue volumes of different size and depth. Figure 6 depicts the calculated wavelength dependence of the penetration depth of light into oxygenated blood, deoxygenated blood and tissue. The depth of light penetration $1 / \mu_{\text {eff }}$ into oxygenated and deoxygenated blood was calculated on the basis of the optical properties of whole blood reported by Faber et al. [35]. The depth of the penetration of light into tissue (water content $80 \%$, wavelength dependence $\mu_{s}^{\prime}: \lambda^{-0.37}$ ) was calculated on the assumption of a blood volume of $5 \%$ (oxygenation 80\%) [36]. Green light (543 nm) has a smaller penetration depth $(0.33 \mathrm{~mm})$ into tissue than do red light $(633 \mathrm{~nm})$, which penetrates to $3.14 \mathrm{~mm}$, and infrared light (800 nm), which penetrates to $4.3 \mathrm{~mm}$.

Gush and King [37] used a red $(632.8 \mathrm{~nm})$ and green $(543.5 \mathrm{~nm})$ helium-neon $(\mathrm{He}-\mathrm{Ne})$ laser to determine the dependence of flow response on wavelength. They measured on forearm and finger pulp and found that flow response differed according to the laser wavelength used, with the green LDF more sensitive to a change in blood flow. It was observed that, since the penetration depth of

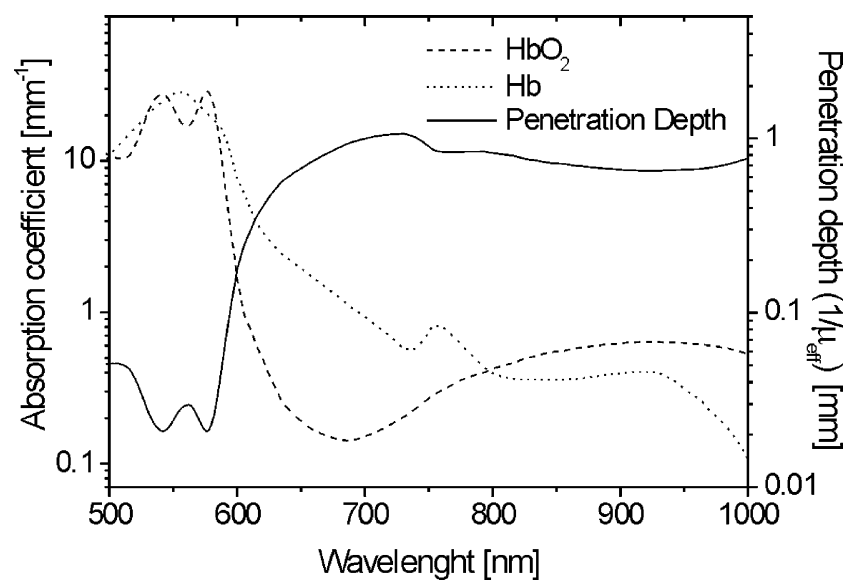

Fig. 6 The calculated wavelength-dependent penetration depth of light into oxygenated blood, deoxygenated blood and tissue (blood volume $5 \%$, oxygenation $80 \%$, water content $80 \%$, reduced scattering coefficient $\left(\mu_{s}^{\prime}\right)$ at $800 \mathrm{~nm}: 0.75 \mathrm{~mm}^{-1}$ ) over a wavelength range from $500 \mathrm{~nm}$ to $1000 \mathrm{~nm}$ 
green light is smaller than that of red light (Fig. 6), the laser Doppler signal obtained with red light showed more high frequency components than did the green light signal. Moreover, a heat provocation test showed that green light was more sensitive to the changes in blood flow during vasodilatation and showed an increase in the high-frequency component in the power spectrum, whereas it falls in the case of red light. This observation was explained based on the results of Einav et al. [38], which showed that, when vessel diameter increases, the more or less parabolic profile of the blood velocity becomes more flat-topped and shows an increase in velocity close to the vessel wall, in contrast to the velocity at the axis, which remains in the same range. Thus, green light, which probes the periphery of the larger microvessels only, due to a much larger absorption than that of red and near infrared light (Fig. 6, optical penetration depth of oxygenated and deoxygenated blood), shows a larger increase in higher Doppler frequency components than does red light, which will multiply scatter throughout the vessel and would also encounter blood with slightly reduced velocity. Figure 7 illustrates the situation.

In a more sophisticated study Koelink et al. [39] used a dual wavelength laser Doppler flowmeter, with wavelengths of $633 \mathrm{~nm}$ and $800 \mathrm{~nm}$, in combination with Monte Carlo simulation to show depth-dependent flow measurement using different wavelengths. Measurements on healthy volunteers showed that two laser systems responded in different ways to an occlusion. Monte Carlo simulations in a three-layer system showed a significant difference in Doppler-shifted photons and number of Doppler scattering events probed in two wavelengths in deeper layers; an $800 \mathrm{~nm}$ laser probed deeper and showed a higher spectral band width than $633 \mathrm{~nm}$.

Another aspect which was studied was changing the source-to-detector separation, which showed the feasibility

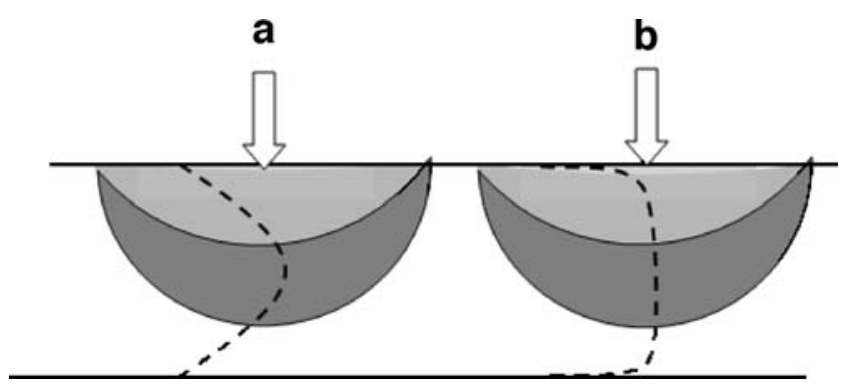

Fig. 7 Effect of vasodilation on the velocity response of green light and red light (dark shading). a Before vasodilation, blood flow shows a parabolic velocity profile (dotted line); green light probes only the periphery of the vessel, where the velocity is low. b Vasodilation produces a flat-topped velocity profile [38], where the green light probes mainly the wall region where the velocity has increased to a larger extent than in the center. In both situations red light probes a larger volume, covering a large part of the velocity profile, which makes the red light less sensitive to flow change than the green light of depth-dependent laser Doppler perfusion monitoring [34, 40]. Liebert et al. [41] developed a multi-channel probe with seven parallel fibers of $200 \mu \mathrm{m}$, fixed close to each other, which gave an emitter-to-detector distance of $0.2 \mathrm{~mm}$ to $1.2 \mathrm{~mm}$. Measurements with a flow model showed that a large separation between source and detector increased sensitivity to deeper flows, whereas a small detector separation measures more superficially.

\section{Deep perfusion measurement techniques}

In order to measure deep tissue perfusion, for example in muscle or brain, a new type of near-infrared laser Doppler monitor was developed. This employed a high source power (or a modulated source) in combination with a large source to detector separation $(20-60 \mathrm{~mm})$. Lohwasser and Soelkner [23] used a $120 \mathrm{~mW}$ laser and showed that they could measure flow up to a depth of $30 \mathrm{~mm}$. Binzoni et al. [21] used a source-to detector-separation of $1.5 \mathrm{~cm}$ to $2.5 \mathrm{~cm}$ to measure muscle r.m.s. velocity. To measure deeply, without exceeding the laser safety limit, pulsed light sources have been considered. Kolinko et al. [42] developed Doppler flowmeters with nanosecond and picosecond laser sources, which could potentially measure deep perfusion and could be used for time-resolved perfusion measurements. Kolkman et al. [43] reported on a pulsed laser Doppler flowmeter based on a pulsed laser diode with a $15 \mathrm{kHz}$ repetition rate and $20 \mathrm{~mW}$ peak power, which would give an average power of $4.7 \mathrm{~mW}$. They sampled each peak signal of back-scattered laser pulses to construct a power spectrum. Their results showed a significant increase in signal-to-noise ratio compared to the signal obtained from a continuous wave (CW) laser source of the same average power. Even though the depths probed by $\mathrm{CW}$ and pulsed LDF were not compared, this method has the potential for deep measurement without exceeding the safety limits.

In a novel laser Doppler flowmetry and remission spectroscopy system (Oxygen-To-See (O2C), LEA Medizintechnik, Giessen, Germany), a wavelength of $820 \mathrm{~nm}(30 \mathrm{~mW})$ was used in the laser Doppler part of the instrument. It was claimed that, using probes with a detection fiber up to a distance of $15 \mathrm{~mm}$ from the source fiber, the instrument offered a sampling depth of up to $15 \mathrm{~mm}$.

\section{Integrated systems}

The idea of miniaturizing the laser Doppler flowmeter and avoiding fiber movement artifacts has led to the concept of an integrated probe for laser Doppler perfusion monitoring [44]. de Mul et al. [44] developed a probe $(\varnothing 16 \mathrm{~mm}$, length $13 \mathrm{~mm}$ ) in which a solid-state diode laser source (AlGaAs, $5 \mathrm{~mW}, 840 \mathrm{~nm}$ ) and detectors were integrated. This avoided 
the use of optical fibers and related motion artifacts. This probe is commercially available as the Diodopp (Applied Laser Technologies, The Netherlands). Higurashi et al. [45] reported on a lighter and smaller integrated probe $(1.5 \mathrm{~mm}$ thick $\times 2 \mathrm{~mm}$ wide $\times 3 \mathrm{~mm}$ long) in which they used a more compact InGaAsP-InP distributed feedback laser diode $(1,310 \mathrm{~nm})$. owing to the edge-emitting behavior of the latter, a micromachined concave mirror was required for beam deflection. Recently, Serov et al. [46] reported on an integrated optoelectronic probe with a vertical cavity surface emitting laser diode (VCSEL). In such a laser, the vertically emitted beam avoids the use of deflection optics. The laser diode and custom-made integrated circuit with detectors, amplifiers and other electronics were integrated into the probe. The probe had a size of $\varnothing 6 \times 6 \mathrm{~mm}^{3}$, with a custom chip of $1.2 \mathrm{~mm} \times 0.8 \mathrm{~mm}$, containing a photodetector pair (PIN photodiodes) and all necessary electronics. A comparative study of the system, with a commercially available laser Doppler instrument with fiber optics, was performed. Results obtained on a subject during physical exercise showed that the signal measured with the integrated probe was not influenced by motion artifacts, whereas the fiber optic instrument showed a significant influence of motion artifacts. However, the signal-to-noise ratio (SNR) of the integrated probe instrument was less than that of the commercial device, because of the small coherence length of the multimode VCSEL $(0.6 \mathrm{~mm})$ compared to the edgeemitting single mode diode lasers used in conventional systems $(6 \mathrm{~mm})$.

\section{Path length-resolved laser Doppler flowmetry}

A totally different refinement was path length-resolved interferometer-based LDF. A laser Doppler-based instrument to measure path length-resolved flow was introduced by Petoukhova et al. [47]. A Mach-Zehnder interferometer with multimode graded index fibers and a low coherent light source was used. By tuning the path length in the reference arm, one could select photons which had traveled a specific optical path length in the sampled medium. It was shown [48] that, in this way, Doppler shifts of multiple scattered light could be obtained that were independent of the absorption properties of the surrounding medium. Varghese et al. [49] have developed a phase-modulated Mach-Zehnder interferometer which can measure the distribution of optical path lengths from a mixture of static and dynamic scatterers with increased signal-to-noise ratio. This method allows one to measure the distribution of optical path lengths of back-scattered photons from a tissue matrix and can resolve the contribution of photons (static and dynamic) with specific path lengths to the Doppler power spectra. The advantage is that one can compensate for the changes in optical properties that cause intra- and inter- individual variation in perfusion measured with conventional laser Doppler flowmeters.

\section{Laser Doppler perfusion imaging}

After the introduction of scanning laser Doppler [28, 29], the perfusion imaging technique has undergone a dramatic progress with the development of technology. Commercial scanning systems became available, which could make color maps of perfusion on an area of tissue $[50,51]$. Wardell and Nilsson [52] introduced duplex laser Doppler perfusion imaging, which allows the study of temporal changes in blood flow by frequently updated single or multipoint recordings. Linden et al. [53] developed enhanced high-resolution LDPI, with a focused laser beam of full width at half maximum (FWHM) of fewer than $40 \mu \mathrm{m}$. A lateral resolution of $40 \mu \mathrm{m}$ was achieved with this beam size. For a review of a range of clinical applications of LDPI, see Briers [9]. Harrison et al. [54] and Kernick and Shore [55] provided a critical assessment of the performance of the imaging systems with a flow model.

The measurement speed of the scanning laser Doppler imagers is limited by the requirement of scanning a beam through the area of investigation. For a step size of $1 \mathrm{~mm}$, it takes a few minutes to scan a 128 point $\times 128$ point area. Some applications of perfusion imaging, such as for drug testing or the diagnosis of a burn wound, demand much faster measurement. With the evolution of complementary metal oxide semiconductor (CMOS) technology, a new full-field approach to laser Doppler perfusion imaging was introduced [56,57], which could make a 2D map of perfusion relatively faster. In this system a diverging laser beam illuminates an area of tissue, and a CMOS sensor captures the back-scattered photons with a lens. A number of frames (typically 1,024) is captured, with a sampling rate of several kilohertz (depending on the selected region of interest on the image array). A 2D perfusion map can be plotted by processing the signal captured by each pixel in time. The advantage of this system is that it can make perfusion maps much faster than the conventional scanning beam systems. Also, since there is no scanning part in the system, movement artifacts can be avoided. The speed and sampling rate of this system are improving very quickly with the development of CMOS technology.

Another full-field approach to laser Doppler imaging was reported [58, 59], based on frequency-shifting off-axis holography. The set-up consists of a heterodyne measurement of the scattered field; two Bragg cells were used for frequency shifting of the reference beam. A charge-coupled device (CCD) sensor was used to record the interference pattern, and the Doppler line width was calculated by a time-domain fast Fourier transform (FFT) on the pixels of the image. The technique has the advantage that it requires 
only a much slower camera than one proposed by Serov et al. [56, 57]. Also, fewer frames are required (32 images) to process the signal than in the earlier report $(1,024$ images) for about $50 \mathrm{~Hz}$ spectral resolution. However, the measurement speed is limited by the frequency scanning by the Bragg cells. Additionally, only one-quarter of the pixels of each frame can be used to describe the image, reducing the area of investigation.

\section{Calibration standards}

Because the laser Doppler perfusion signal is a relative measure of flux, standardization is required in comparing the level of perfusion in different measurements and from different instruments. A calibration system for this requirement has been a topic of research since the early days of LDF and has various purposes: (1) to check the instrument's stability; (2) to establish the linearity of the instrument's response to blood flow; (3) to establish relationships between different instruments, and (4) to relate the reading of the instrument to real perfusion, if possible.

There is no gold standard yet available for the calibration of the laser Doppler instrument for perfusion measurements. Since the distribution of blood vessels in tissue and optical properties is heterogeneous, it is difficult to calibrate an instrument to measure absolute blood flow per unit volume of tissue. Often, a comparison between laser Doppler flowmetry and an alternative method is complicated, because of the difference in techniques and probed volume [60-63]. Another approach which was tested for an absolute flow measurement was measuring on either a well-defined tissue preparation [64] or on flow models [26, 65]. However, these methods cannot be considered as calibration methods on a day-to-day basis for clinical use. Therefore, a simple method has been in use for frequent and easy calibration of laser Doppler instrumentation. This is an aqueous suspension of polystyrene microspheres in Brownian motion called a motility standard. The Doppler shift generated by the particles in Brownian motion is used to calibrate the system's overall integrity for a comparison of measurements at different time intervals. However, this method has some major shortcomings, as mentioned by Liebert et al. [66]. Owing to its completely dynamic properties, such suspensions induce Doppler shifts leading to a pure homodyne measurement, whereas, in real tissue, the majority of photons are un-shifted and produces totally different heterodyne spectra.

Several studies have been carried out to develop a calibration device for absolute flow measurement. Most of the devices are based on flow models. Nilsson et al. [27] used a mechanical fluid model based on a polyacetal disk with polythene tubing to simulate tissue blood flow. Obeid [65] used a similar flow model to check the linearity of the velocity response of different signal processing algorithms. Another approach was the use of solid-based systems in which a layer was rotated or translated between a sandwich of stationary layers [67]. De Mul et al. [68], and Steenbergen and De Mul [69] reported on a standard consisting of a set of layers containing scattering and absorbing particles, either at rest or moving with respect to each other. The advantage of this approach is the absolute predictability of the results with Monte Carlo simulations. Larsson et al. [70] used this system to assess the influence of tissue optical properties on the depth sensitivity and mean sampling depth of a laser Doppler perfusion monitor. All the above-mentioned models are more useful as research tools than as calibration devices for simple dayto-day use with the laser Doppler instrument.

Liebert et al. [66] developed a simple phantom made of a solution of latex spheres embedded in porous polyethylene material (Vyon). This mixture of static and dynamic scattering phantom produces a more realistic spectrum, similar to that obtained in tissue. An ideal calibration system, taking into consideration the flow, size of red blood cells and optical properties of the tissue, has yet to be developed and seems rather difficult to realize.

A completely different approach was the so-called optoelectronic calibration of laser Doppler devices [71]. In this method, light from an intensity modulated light-emitting diode is offered to the detection channel of the device. Varying the modulation frequency and amplitude simulates the effect of varying speed and concentration of red blood cells. Such a methodology only tests the detection and signal processing module of laser Doppler flowmetry devices.

\section{Biological zero problem}

It was found that there is a residual signal in laser Doppler perfusion measurements from the tissue called biological zero (BZ), which is present even when there is no flow [72]. Measurements on excised tissue [72] and cadaver skin [73] suggested that the BZ signal primarily originates from Brownian motion and movement of red blood cells. Normally, in laser Doppler perfusion measurements it is suggested that one should subtract this BZ signal from the normal perfusion value to obtain a better understanding of the perfusion, especially in the case of very low perfusion measurements [74-76]. Fagrell and Nilsson [77] suggested that the $\mathrm{BZ}$ is due to the residual movement of entrapped blood cells and other moving constituents of living tissue, such as vessel wall activity, hair follicles and sweat gland production.

Kernick et al. [78] did a detailed study with a BZ-based flow model, on in vitro and in vivo measurements. Their 
results showed that $\mathrm{BZ}$ varies linearly with temperature in in vivo and in vitro measurements, which is a characteristic of Brownian motion. Also in a flow model with increasing temperature, the BZ output of skin tissue surrounding the flow model increased, contributing to the LDF output, but the flow characteristics remained linear. On the basis of their observations, they strongly suggest that the BZ signal in skin is from the Brownian motion of tissue structures and macromolecules in the interstitial spaces. Before carrying out a quantitative comparison of the BZ based on Kernick et al. [78], one should note that they used $0.8 \mathrm{~mm}$ fibers with $1.2 \mathrm{~mm}$ center-to-center fiber separation in combination with a $\mathrm{He}-\mathrm{Ne}$ laser for their measurements. Earlier, Liebert et al. [41] had shown that the optical arrangement of the probe has a significant influence on BZ.

Even though Kernick et al. [78] showed that BZ is caused by Brownian motion, the question that remains unanswered is whether the Brownian motion that contributes to normal perfusion is quantitatively the same as the Brownian motion during an occlusion. We strongly believe that unless the behavior of this Brownian motion is fully understood in these two situations, it is difficult to reach a conclusion on the matter of subtracting biological zero from the normal perfusion value.

Zhong et al. [79] proposed an elegant method for solving the biological zero problem. They considered the decomposition of the red blood cells speed into a random fluctuation (Brownian motion) and a constant translational velocity. On the basis of their model, they suggested that the mere subtraction of biological zero will lead to an underestimation of the perfusion. As an extension of their model Binzoni et al. [22] developed an analytical solution for different moments of the power spectrum for the Brownian motion for larger inter-optode distances. However, since Kernick et al. [78] had shown that temperature influences BZ, the validity of these models in real situations can be questioned.

\section{Motion artifacts}

One of the inherent limitations of laser Doppler perfusion measurements is the influence of the movement artifacts associated with the perfusion signal. This can be either by tissue motion or by fiber movements in a fiber-optic probe. Newson et al. [80] investigated the influence of fiber movements on the perfusion signal by controlled movement of the fiber attached to a shaker. It was found that fiber movements significantly contributed to the low-frequency part of the beat frequency spectra from which the blood flow signal was extracted. Gush and King [81] suggested a modification of fiber-optic probes to reduce movement artifacts. They suggested that the use of small aperture fibers, with fewer modes, and keeping the fiber close to the skin would reduce the movement artifacts to some extent. Commercial laser Doppler systems use a high-pass filter (often $20 \mathrm{~Hz}$ ) to filter out the low-frequency part of spectra, to deal with motion artifacts. The problem of fiber-based noise from movement artifacts can be solved with the use of an integrated probe [44-46], where light delivery and detection are on the same probe.

The influence of tissue motion on the blood flow signal was addressed by Öberg [82]. He studied the contribution of tissue motion generated by respiratory and circulatory systems of the human body on the perfusion signal. The measurements with a shaking system mimicking a linear tissue motion in combination with a flow model showed that the flow signal increases linearly with the increase of vibration movements $(0-350 \mu \mathrm{m} / \mathrm{s})$ with a constant flow velocity.

Tissue motion and the physical movements of the subjects produce more artifacts in a non-contact measurement technique such as laser Doppler perfusion imaging than with monitoring using the probe fixed on the skin [83]. In scanning LDPI, which normally takes a few minutes to finish one complete scan, the motion artifacts are of great concern. Karlsson and Wårdell [84] used linearly polarized laser light in combination with a polarization filter in front of the detectors in a cross-polarization state to filter out the specularly reflected light. This also filtered out the reflected light, which was Doppler shifted because of the motion of the structure, and allowed only randomly polarized multiple scattered photons to reach the detector. However, the polarization filter would also filter out some photons that were Doppler shifted by superficial perfusion, which would reduce the SNR and make the interpretation of the signal difficult. The emerging full-field techniques, mentioned before, which can make a perfusion map very quickly when compared with the scanning techniques, will definitely benefit from the reduced influence of movement artifacts.

\section{Multiple Doppler shifts: a theoretical limitation}

The theoretical model developed by Bonner and Nossal [17] is the basis of all the conventional laser Doppler perfusion monitors and imagers. One of the assumptions in this model in the calculation of blood flow is that single Doppler shifted photons are dominant. However, in reality, this assumption is not valid in the case of highly perfused tissue, where large numbers of photons interact with more than one moving red blood cell. Nilsson [27] developed a signal processor to correct for the effect of multiple Doppler shifting. He designed a processor in which flux is linearized based on the signal from the concentration of moving red blood cells (CMBC). Evaluation of the processor by 
Nilsson [27] and also by Ahn et al. [64] showed that this correction method works well till a volume fraction of around $1 \%$ is reached. A later study by Barnett et al. [85] showed, however, that at higher perfusion rates this processor underestimates the flow. Petoukhova et al. [86] did a comparative study of the output flow signal of two instruments, one with a linearizer and one without. They measured on the cortex of pigs' kidneys with a range of sizes and weights and used an ultrasonic flowmeter as a reference. A strong correlation was found between the output signals of the two instruments for a variety of flow values. This suggested that the linearization algorithm was not influencing the perfusion signal for a range of physiologically relevant flow values. The fact that the concentration signal was becoming saturated at higher flow values $[86,87]$ and that the response of the power spectral density algorithm was extremely poor above concentrations of $0.2 \%$ volume fraction of RBCs [85], questions the usefulness of using the linearization algorithm under these conditions.

\section{Influence of the tissues' optical properties}

The scattering and absorption of tissue affects the sensitivity of the laser Doppler perfusion signal as well as the depth of probing of the instrument. Larsson et al. [70] studied the influence of optical properties on this signal. They used a rotating phantom [69] with a stack of static scattering layers made of a mixture of polyvinyl alcohol and hollow polystyrene microspheres with well-defined optical properties. The results showed that the perfusion signal was significantly influenced by optical properties for a homogeneous flow distribution independent of the source-todetector fiber separation. The change in optical properties changes the path length traveled by the photons and influences the perfusion signal, irrespective of the velocity of the moving scatterers [17, 88, 89]. A path lengthresolved laser Doppler, as suggested by Petoukhova et al. [47] and Varghese et al. [49] will give a perfusion signal with knowledge of the optical path length the photons have traveled, which can compensate for the influence of optical properties. However, these are interferometric approaches that cannot be simply added to the existing laser Doppler monitors. Larsson et al. [90] presented an analytical approach for path length compensation [88], predicting the average path length with different source-detector separations. They used diffuse reflectance measurements and Monte Carlo simulations to predict the path length for different fiber separations. A perfusion signal compensated for path length and independent of optical properties was shown with a simulation model of a single layer system. However, for the vivo results to be validated, the simulation model has to be further expanded for heterogeneous optical properties with multiple layers.

In a laser Doppler imager where the detector is in the far field, the changes in the optical properties of the tissue will be reflected by a change in spot size and, in turn, the number of coherence areas (speckles) on the detector. Since the modulation depth of the signal depends on the number of speckles involved in the detection process, as explained earlier, the perfusion signal is influenced by the optical properties of the tissue. The numbers and sizes of speckles on the far-field detector of the imager depend on the tissue's optical properties, the distance between the scattering medium and the detector, and the detector and lens geometries. Wardell et al. [29] compensated for the variation in the number of coherence areas with distance between the medium and the detector by using a slightly diverging beam. They took the number of coherence areas as an instrumental constant, which varies with changes in sourceto-detector distance. The use of a diverging beam gave only partial compensation, since it only corrected for variation of the distance between the tissue and the detector and not for the variation in the tissue's optical properties. The concept that the number of coherence areas is an instrumental constant is true in the case of a fiber-optic geometry where the number of speckles is determined by the distance of the end facet of the detector fibers to the detector [16]. However, the tissue's optical properties have an important role in the number of coherence areas generated on the photodetector in an LDPI instrument. Rajan et al. [91] have shown that the scattering level of the tissue strongly affects the signal of a laser Doppler imager as a consequence of the number of speckles involved in the detection process. They used a range of beam sizes to illuminate an optical phantom and studied the influence of speckle size on the perfusion signal. It was observed that, with a typical beam size of $0.5 \mathrm{~mm}$, the perfusion signal varied by a factor of 4 when the reduced scattering level varied from $0.5 \mathrm{~mm}^{-1}$ to $4.0 \mathrm{~mm}^{-1}$. This variation dropped to a factor of 1.5 when the beam size was increased to $4.0 \mathrm{~mm}$. This showed the influence of the scattering level on the speckle size, which, in turn, influenced the response of the laser Doppler system to the same perfusion level under different optical surroundings.

Recently, Rajan et al. [92] reported that the spatial correlations of the intensity of far-field dynamic speckle patterns generated by mixed static and dynamic turbid media illuminated by coherent light can be predicted. Based on a theoretical /computational framework, the variance of photocurrent fluctuations was modeled for a far-field detector collecting back-scattered photons on the basis of Monte Carlo-derived photon statistics, taking into account the speckle phenomenon. The speckle size variations were estimated for different scattering levels and anisotropies. 
The experimental validation of the theoretical model in a configuration similar to that of the laser Doppler perfusion imager showed the potential of the method in predicting the effect of the tissue's optical properties on the modulation depth of the signal of the laser Doppler perfusion imager through the speckle phenomenon.

\section{Conclusions}

The techniques for measuring perfusion by laser Doppler instruments have made great progress since their introduction. The improvements in laser technology and fiber optics, and in signal processing, have made LDF into a reliable and user-friendly technology. The introduction of the imaging technique opened up clinical research applications where non-contact measurements are a necessity and where perfusion information within an area of tissue is required. The limitations of the technique were thoroughly addressed by the researchers, enabling them to make many improvements. However, some of the more fundamental limitations given in this review still demand a revisit, and measuring perfusion in absolute units remains a scientific challenge. The problem of multiple Doppler shifts remains unresolved as well. The velocity-resolved perfusion measurements cited by a few authors need more research before being applied to real tissue. Also, the problem of the tissue's optical properties should be addressed in the case of scanning field laser Doppler perfusion imagers. The emerging full-field laser Doppler imaging technique has the potential to overcome motion artifacts and the slow scanning speed of conventional scanning imagers. Here, the influence of optical properties on the number of coherence areas will be less, because of the use of a full-field beam. Regardless of all these limitations, laser Doppler methods remain a highly sought after technique for microcirculatory blood flow measurements.

Acknowledgments The authors would like to acknowledge S. Manohar and R.G.M Kolkman for comments on the manuscript.

Open Access This article is distributed under the terms of the Creative Commons Attribution Noncommercial License which permits any noncommercial use, distribution, and reproduction in any medium, provided the original author(s) and source are credited.

\section{References}

1. Drain L (1980) The laser Doppler technique, Wiley, USA

2. Larsen OA, Lassen NA, Quaade F (1966) Blood flow through human adipose tissue determined with radioactive xenon. Acta Physiol Scand 66:337-345
3. Rudolph AM, Heymann MA (1967) The circulation of the fetus in utero. Methods for studying distribution of blood flow, cardiac output and organ blood flow. Circ Res 21:163-184

4. Heymann MA, Payne BD, Hoffman JI, Rudolph AM (1977) Blood flow measurements with radionuclide-labeled particles. Prog Cardiovasc Dis 20:55-79

5. Silverman DG, Cedrone FA, Hurford WE, Bering TG, LaRossa DD (1981) Monitoring tissue elimination of fluorescein with the perfusion fluorometer: a new method to assess capillary blood flow. Surgery 90:409

6. Bollinger A, Butti P, Banas JP, Trachsler H, Seigenthaler W (1974) Red cell velocity in nailfold capillaries in man measured by a television microscope technique. Microvasc Res 7:61-72

7. Black CM, Clark RP, Darton K, Goff MR, Norman TD, Spikes HA (1990) A pyroelectric thermal imaging system for use in medical diagnosis. J Biomed Eng 12:281-286

8. Payne PA, Faddoul RY, Jawad SM (1985) A single channel pulsed Doppler ultrasound instrument for measurement of skin blood flow. Practical aspects of skin blood flow measurement (London: Biological Engineering Society)

9. Briers JD (2001) Laser Doppler, speckle and related techniques for blood perfusion mapping and imaging. Physiol Meas 22:3566

10. Shepherd AP, Öberg PÅ (1990) Laser-Doppler blood flowmetry. Kluwer Academic Publishers, Boston

11. Zhao Y, Chen Z, Saxer C, Xiang S, de Boer JF, Nelson JS (2000) Phase-resolved optical coherence tomography and optical Doppler tomography for imaging blood flow in human skin with fast scanning speed and high velocity sensitivity. Opt Lett 25:114-116

12. Obeid AN, Barnett NJ, Dougherty G, Ward G (1990) A critical review of laser Doppler flowmetry. J Med Eng Technol 14:178-181

13. Vongsavan N, Matthews B (1993) Some aspects of the use of laser Doppler flow meters for recording tissue blood flow. Exp Physiol 78:1-14

14. Leahy MJ, de Mul FFM, Nilsson GE, Maniewski R (1999) Principles and practice of the laser-Doppler perfusion technique. Technol Health Care 7:143-162

15. Vennemann P, Lindken R, Westerweel J (2007) In vivo whole-field blood velocity measurement techniques. Exp Fluids 42:495-511

16. Serov A, Steenbergen W, de Mul FFM (2001) Prediction of the photodetector signal generated by Doppler-induced speckle fluctuations: theory and some validations. J Opt Soc Am A 18:622-630

17. Bonner RF, Nossal R (1981) Model for laser Doppler measurements of blood flow in tissue. Appl Opt 20:2097-2107

18. Dörschel K, Müller G (1996) Velocity resolved laser Doppler blood flow measurements in skin. Flow. Meas Instrum 7:257-264

19. Larsson M, Strömberg T (2006) Toward a velocity-resolved microvascular blood flow measure by decomposition of the laser Doppler spectrum. J Biomed Opt 11:014024

20. Liebert A, Zolek N, Maniewski R (2006) Decomposition of a laser-Doppler spectrum for estimation of speed distribution of particles moving in an optically turbid medium: Monte Carlo validation study. Phys Med Biol 51:5737-5751

21. Binzoni T, Leung TS, Boggett D, Delpy DT (2003) Non-invasive laser Doppler perfusion measurements of large tissue volumes and human skeletal muscle blood RMS velocity. Phys Med Biol 48:2527-2549

22. Binzoni T, Leung TS, Seghier ML, Delpy DT (2004) Translational and Brownian motion in laser-Doppler flowmetry of large tissue volumes. Phys Med Biol 49:5445-5458

23. Lohwasser R, Soelkner G (1999) Experimental and theoretical laser-Doppler frequency spectra of a tissue like model of a human head with capillaries. Appl Opt 38:2128-2137

24. Stern MD (1975) In vivo evaluation of microcirculation by coherent light scattering. Nature 254:56-58 
25. Watkins D, Holloway GA Jr (1978) An instrument to measure cutaneous blood flow using the Doppler shift of laser light. IEEE Trans Biomed Eng BME-25:28-33

26. Nilsson GE, Tenland T, Oberg PA (1980) Evaluation of a laser Doppler flowmeter for measurement of tissue blood flow. IEEE Trans Biomed Eng BME-27:597-604

27. Nilsson GE (1984) Signal processor for laser Doppler tissue flowmeters. Med Biol Eng Comput 22:343-348

28. Essex TJH, Byrne PO (1991) A laser Doppler scanner for imaging blood flow in skin. J Biomed Eng 13:189-193

29. Wardell K, Jakobsson A, Nilsson GE (1993) Laser Doppler perfusion imaging by dynamic light scattering. IEEE Trans Biomed Eng 40:309-316

30. Koelink MH, de Mul FFM, Leerkotte BJM, Greve J, Jentink HW, Graaff R, Dassel ACM, Aarnoudse JG (1994) Signal processing for a laser-Doppler blood perfusion meter. Signal Process 38:239252

31. Chen YY, Lin YH, Jan IC, Liu RS, Chou NK, Jan GJ (2004) Adaptive processing bandwidth adjustment for laser Doppler flowmetry. Med Biol Eng Comput 42:277-281

32. Duteil L, Bernengo J, Schalla W (1985) A double wavelength laser Doppler system to investigate skin microcirculation. IEEE Trans Biomed Eng BME-32:439-447

33. Obeid AN, Bogget D, Barnett NJ, Dougherty G, Rolfe P (1988) Depth discrimination in laser Doppler skin blood flow measurement using different lasers. Med Biol Eng Comput 26:415-419

34. Jentink HW, de Mul FFM, Hermsen RGAM, Graaff R, Greve J (1990) Monte Carlo simulations of laser Doppler blood flow measurements in tissue. Appl Opt 29:2371-2381

35. Faber DJ, Aalders MCG, Mik EG, Hooper BA, van Gemert MJC, van Leeuwen TG (2004) Oxygen saturation-dependent absorption and scattering of blood. Phys Rev Lett 93:028102-1-028102-4

36. Kolkman RGM (1998) Photoacoustic \& pulsed-laser Doppler monitoring of blood concentration and perfusion in tissue. $\mathrm{PhD}$ thesis, University of Twente

37. Gush RJ, King TA (1991) Discrimination of capillary and arteriovenular blood flow in skin by laser Doppler flowmetry. Med Biol Eng Comput 29:387-392

38. Einav S, Berman HJ, Fuhro RL, DiGiovanni PR, Fine S, Fridman JD (1975) Measurement of velocity profiles of red blood cells in the microcirculation by laser doppler anemometry (LDA). Biorheology 12:207-210

39. Koelink M, de Mul FFM, Greve J, Graaff R, Dassel ACM, Aarnoudse JG (1994) Laser Doppler blood flowmetry using two wavelengths: Monte-Carlo simulations and measurements. Appl Opt 33:3549-3558

40. Jakobsson A, Nilsson G (1993) Prediction of sampling depth and photon pathlength in laser Doppler flowmetry. Med Biol Eng Comput 31:301-307

41. Liebert A, Leahy M, Maniewski R (1998) Multichannel laserDoppler probe for blood perfusion measurements with depth discrimination. Med Biol Eng Comput 36:740-747

42. Kolinko VG, de Mul FFM, Greve J, Priezzhev AV (1998) Feasibility of picosecond laser-Doppler flowmetry provides basis for time-resolved Doppler tomography of biological tissue. J Biomed Opt 3:187-190

43. Kolkman RGM, Hondebrink E, Bolt RA, Steenbergen W, de Mul FFM (2001) Pulsed-laser Doppler flowmetry provides basis for deep perfusion probing. Rev Sci Instrum 72:4242-4244

44. de Mul FFM, van Spijker J, van der Plas D, Greve J, Aarnoudse JG, Smits TM (1984) Mini laser-Doppler (blood) flow monitor with diode laser source and detection integrated in the probe. Appl Opt 23:2970-2973

45. Higurashi E, Sawada R, Ito T (2003) An integrated laser blood flowmeter. J Lightwave Technol 21:591-595
46. Serov AN, Nieland J, Oosterbaan S, de Mul FFM, van Kranenburg H, Bekman HHPT, Steenbergen W (2006) Integrated optoelectronic probe including a vertical cavity surface emitting laser for laser Doppler perfusion. monitoring. Monitoring. IEEE Trans Biomed Eng 53:2067-2074

47. Petoukhova AL, Steenbergen W, de Mul FFM (2001) Path-length distribution and path-length-resolved Doppler measurements of multiply scattered photons by use of low-coherence interferometry. Opt Lett 26:1492-1494

48. Petoukhova AL, Steenbergen W, van Leeuwen TG, de Mul FFM (2002) Effects of absorption on coherence domain path length resolved dynamic light scattering in the diffuse regime. Appl Phys Lett 81:595-597

49. Varghese B, Rajan V, van Leeuwen TG, Steenbergen W (2007) Path-length-resolved measurements of multiple scattered photons in static and dynamic turbid media using phase-modulated lowcoherence interferometry. J Biomed Opt 12:024020

50. Huang X, Lu L, Gush RJ, Boggett DM (1996) A new, fast, high resolution laser Doppler imager for clinical and research use. Proceedings of the 6th World Congress for Microcirculation (Munich, Germany)

51. Nilsson G (1997) Laser Doppler perfusion imaging for assessment of cutaneous microcirculation. Phlebologie 26:87-91

52. Wardell K, Nilsson GE (1996) Duplex laser Doppler perfusion imaging. Microvasc Res 52:171-82

53. Linden M, Golster H, Bertuglia S, Colantuoni A, Sjöberg F, Nilsson G (1996) Evaluation of enhanced high-resolution laser Doppler imaging in an in vitro tube model with the aim of assessing blood flow in separate microvessels. Microvasc Res $56: 261-270$

54. Harrison DK, Abbot NC, Beck JS, McCollum PTA (1993) Preliminary assessment of laser Doppler perfusion imaging in human skin using the tuberculin reaction as a model. Physiol Meas 14:241-252

55. Kernick DP, Shore AC (2000) Characteristics of laser Doppler perfusion imaging in vitro and in vivo. Physiol Meas 21:333-340

56. Serov A, Steenbergen W, de Mul FFM (2002) Laser Doppler perfusion imaging with a complimentary metal oxide semiconductor image sensor. Opt Lett 25:300-302

57. Serov A, Steinacher B, Lasser T (2005) Full-field laser Doppler perfusion imaging and monitoring with an intelligent CMOS camera. Opt Express 13:3681-3689

58. Atlan M, Gross M, Forget BC, Vitalis T, Rancillac A, Dunn AK (2006) Frequency-domain wide-field laser Doppler in vivo imaging. Opt Lett 31:2762-2764

59. Atlan M, Gross M (2006) Laser Doppler imaging revisited. Rev Sci Instrum 77:116103

60. Cochrane T, Fail T, Sherriff SB (1987) Comparison of laser Doppler and Doppler ultrasound in lower limb vascular diagnosis. Clin Phys Physiol Meas 8:231-238

61. Seifalian AM, Stansby G, Jackson A, Howell K, Hamilton G (1994) Comparison of laser Doppler perfusion imaging, laser Doppler flowmetry, and thermographic imaging for assessment of blood flow in human skin. Eur J Vasc Surg 8:65-69

62. Doughertyt G, Barnett NJ, Pettingerg SJ (1992) A prototype instrument combining laser Doppler flowmetry and reflection pulse oximetry. Clin Phys Physiol Meas 13:105-114

63. Holloway GA, Watkins DW (1977) Laser Doppler measurement of cutaneous blood flow. J Invest Dermatol 69:306-309

64. Ahn H, Johansson K, Lundgren O, Nilsson GE (1987) In vivo evaluation of signal processors for laser Doppler tissue flowmeters. Med Biol Eng Comput 25:207-211

65. Obeid AN (1993) In vitro comparison of different signal processing algorithms used in laser Doppler flowmetry. Med Biol Eng Comput 31:43-52 
66. Liebert A, Leahy M, Maniewski R (1995) A calibration standard for laser-Doppler perfusion measurements. Rev Sci Instrum 66:5169-5173

67. Shepherd AP, Riedel GL, Kiel JW, Haumschild DJ, Maxwell LC (1987) Evaluation of an infrared laser-Doppler blood flowmeter. Am J Physiol Gastrointest Liver Physiol 252:G832-G839

68. de Mul FFM, Koelink MH, Kok ML, Harmsma PJ, Greve J, Graaff R, Aarnoudse JG (1995) Laser-Doppler velocimetry and Monte Carlo simulations on models for blood perfusion in tissue. Appl Optics 34:6595-6611

69. Steenbergen W, de Mul FFM (1998) New optical tissue phantom and its use for studying laser Doppler blood flowmetry. Proc SPIE 3196:12-23

70. Larsson M, Steenbergen W, Strömberg T (2001) Influence of optical properties and fibre separation on laser Doppler flowmetry. J Biomed Opt 7:236-243

71. Liebert A, Lukasiewicz P, Boggett D, Maniewski R (1999) Optoelectronic standardization of Laser Doppler perfusion monitors. Rev Sci Instrum 70:1352-1353

72. Tenland T, Salerud EG, Nilsson GE, Oberg PA (1983) Spatial and temporal variations in human skin blood flow. Int J Microcirc Clin Exp 2:81-90

73. Caspary L, Creutzig A, Alexander K (1988) Biological zero in laser Doppler fluximetry. Int J Microcirc Clin Exp 7:367-371

74. Fagrell B (1990) Perimed's LDV flowmeter. In: Shepherd A P, Öberg PÅ (eds) Laser-Doppler blood flowmetry. Kluwer Academic Publishers, Boston

75. Nilsson GE (1990) Peripheral vascular diseases. In: Shepherd AP, Öberg PÅ (eds) Laser-Doppler blood flowmetry. Kluwer Academic Publishers, Boston

76. Abbot NC, Swanson-Beck J (1993) Biological zero in laser Doppler measurements in normal, ischaemic and inflamed human skin. Int J Microcirc Clin Exp 2:89-98

77. Fagrell S, Nilsson G (1995) Advantages and limitations of one point laser Doppler perfusion monitoring in clinical practice. Vasc Med Rev 6:97-101

78. Kernick DP, Tooke JE, Shore AC (1999) The biological zero signal in laser Doppler fluximetry - origins and practical implications. Pflügers Arch 437:624-631

79. Zhong J, Seifalian AM, Salerud GE, Nilsson GE (1998) A mathematical analysis on the biological zero problem in laser Doppler flowmetry. IEEE Trans Biomed Eng 45:354-364
80. Newson TP, Obeid A, Wolten RS, Boggett D, Rolfe P (1987) Laser Doppler velocimetry: the problem of fibre movement artifacts. J Biomed Eng 9:169-172

81. Gush RJ, King TA (1987) Investigation and improved performance of optical fibre probes in laser Doppler blood flow measurement. Med Biol Eng Comput 678:29-36

82. Öberg PA (1999) Tissue motion-a disturbance in the laserDoppler blood flow signal? Technol Health Care 7:185-192

83. Karlsson MGD, Larsson M, Strömberg T, Wårdell K (2002) Influence of tissue movements on laser Doppler perfusion imaging. Proc SPIE 4624:106-114

84. Karlsson MGD, Wårdell K (2005) Polarized laser Doppler perfusion imaging - reduction of movement-induced artifacts. J Biomed Opt 10:064002

85. Barnett NJ, Dougherty G, Pettinger SJ (1990) Comparative study of two laser Doppler blood flowmeters. J Med Eng Technol 14: 243-249

86. Petoukhova AL, Steenbergen W, Morales F, Graaff R, de Jong ED, Elstrodt JM, de Mul FF, Rakhorst G (2003) Instrumentindependent flux units for laser Doppler perfusion monitoring assessed in a multi-device study on the renal cortex. Microvasc Res 66:83-90

87. Boggett D, Obeid AN, Blond J, Rolf P (1986) Calibration of a laser Doppler skin blood flow meter using a simple fluid model and digital signal processing. In Copeland $\mathrm{K}$ (ed) Electronics in medicine and biology — selected papers. IERE, London, pp 241-247

88. Nilsson H, Larsson M, Nilsson GE, Strömberg T (2002) Photon pathlength determination based on spatially resolved diffuse reflectance. J Biomed Opt 7:478-485

89. Nossal R, Bonner RF, Weiss GH (1989) Influence of path length on remote optical sensing of properties of biological tissue. Appl Opt 28:2238-2244

90. Larsson M, Nilsson H, Strömberg T (2003) In vivo determination of local skin optical properties and photon path length by use of spatially resolved diffuse reflectance with applications in laser Doppler flowmetry. Appl Opt 42:124-134

91. Rajan V, Varghese B, van Leeuwen TG, Steenbergen W (2006) Speckles in Laser Doppler perfusion imaging. Opt Lett 31:468-470

92. Rajan V, Varghese B, van Leeuwen TG, Steenbergen W (2007) Quantification of spatial intensity correlations and photodetector intensity fluctuations of coherent light reflected from turbid particle suspensions. Phys Rev E 75:060901-060904 